\title{
Wildfire Detection and Tracking over Greece Using MSG-SEVIRI Satellite Data
}

\author{
Nicolaos I. Sifakis ${ }^{1, *}$, Christos Iossifidis ${ }^{2}$, Charalabos Kontoes ${ }^{1}$ and Iphigenia Keramitsoglou ${ }^{1}$ \\ 1 Institute for Space Applications and Remote Sensing, National Observatory of Athens, I. \\ Metaxa \& Vas. Pavlou, 15236 Athens, Greece; E-Mails: kontoes@noa.gr (C.K.); ik@ noa.gr (I.K.) \\ 2 School of Rural and Surveying Engineering, National Technical University of Athens, \\ 15780 Zographou, Greece; E-Mail: chiossif@gmail.com \\ * Author to whom correspondence should be addressed; E-Mail: sifakis@ noa.gr; \\ Tel.: +30-210-810-9187.
}

Received: 7 January 2011; in revised form: 17 February 2011 / Accepted: 21 February 2011 / Published: 9 March 2011

\begin{abstract}
Greece is a high risk Mediterranean country with respect to wildfires. This risk has been increasing under the impact of climate change, and in summer 2007 approximately 200,000 ha of vegetated land were burnt. The SEVIRI sensor, on board the Meteosat Second Generation (MSG) geostationary satellite, is the only spaceborne sensor providing five and 15-minute observations of Europe in 12 spectral channels, including a short-wave infrared band sensitive to fire radiative temperature. In August 2007, when the bulk of the destructive wildfires started in Greece, the receiving station, operated by the Institute for Space Applications and Remote Sensing, provided us with a time series of MSG-SEVIRI images. These images were processed in order to test the reliability of a real-time detection and tracking system and its complementarity to conventional means provided by the Fire Brigade. EUMETSAT's Active Fire Monitoring (FIR) image processing algorithm for fire detection and monitoring was applied to SEVIRI data, then fine-tuned according to Greek conditions, and evaluated. Alarm announcements from the Fire Brigade's archives were used as ground truthing data in order to assess detection reliability and system performance. During the examined period, MSG-SEVIRI data successfully detected $82 \%$ of the fire events in Greek territory with less than $1 \%$ false alarms.
\end{abstract}

Keywords: wildfire; SEVIRI; Greece 


\section{Introduction}

Wildfires in Europe burn an average of half a million ha of forested or non-forested land through approximately 50,000 fire events per year. Fires larger than 50 ha account for over $75 \%$ of the total burnt area [1]. Mediterranean countries, because of their biogeographic setting, are at the highest risk and suffer the greatest extent of losses in terms of human lives, livestock, residences, infrastructures, as well as forested and agricultural land. These losses have a significant impact on the economy of the countries and, through the destruction of marketable assets, affect the broader European Community. While the vast majority of wildfires are anthropogenic, the risk of such fires is expected to increase in forthcoming years under the impact of climate change; vegetation becomes more inflammable (due to thermal stress and drought) and fire services are faced with difficulties when trying to suppress a fire due to increased inflammability and water shortage [2]. Moreover, forest ecosystems are now more important than ever as they constitute temperature regulators and filters for most atmospheric pollutants.

Greece suffered a massive loss of forested land during the summer of 2007 when 194,000 ha of land (approximately $6 \%$ of the country's vegetated land) were burned [3], and thousands of people were affected [4]. Civil Protection Services, Forest Fire Services and Environmental Services were faced with the management of multiple fires, the evolution of simultaneous extensive fire fronts and the monitoring of heavy smoke emitted during these events. Timely and reliable detection of new outbursts was particularly crucial for effective wildfire management, particularly in largely inaccessible mountainous areas. Near real time tracking and monitoring of active fronts was also very important during crisis management concerning the optimal distribution of ground and aerial forces.

The role of satellite observations in the resolution of the previous issues has considerably increased during the last twenty years as the spatial, spectral and temporal characteristics of the sensors have been constantly improving, and new methods for the exploitation of satellite data have been developed [5,6]. AVHRR was the first satellite sensor in polar orbit to provide data from the spectral regions of short-wave infrared or SWIR (centered at $3.9 \mu \mathrm{m}$ ) and of thermal infrared or TIR (centered at $10.8 \mu \mathrm{m}$ ), both associated to the detection of temperature variations on the Earth's surface. Various algorithms using AVHRR data for detecting hot spots associated to wildfires have hitherto been proposed [7-9]. Algorithms for fire detection using other polar satellite data have also been proposed, and a series of satellite based fire products (using ATSR or MODIS data) are currently available [10-12]. Most of these algorithms and products show an overestimation of fire detections (i.e., false alarms) in Southern Europe, but the most important limitation of polar satellite systems, with regard to the needs of continuous and in-real-time monitoring of wildfires, is their infrequent overpasses, varying inversely with the spatial resolution of the sensor (Figure 1). In this respect only geostationary systems with their inherent high temporal resolution can be helpful; the Spinning Enhanced Visible and Infrared Imager (SEVIRI), on board the geostationary Meteosat Second Generation (MSG) satellite, allows for observations over Europe every 15 minutes (or every 5 minutes in the Rapid Scanning Service mode at the expense of coverage). SEVIRI has 12 spectral bands, two of which are operative in the SWIR and in the TIR wavelengths sensitive to fire and to Earth's surface radiative temperature, respectively. The other bands cover the spectral areas of visible (VIS), near infrared (NIR) and water vapor absorption (WV) (Table 1). 
Figure 1. Variation of the spatial vs. the temporal resolution of satellite sensors. Examples of wildfire images acquired by each sensor category are also given.

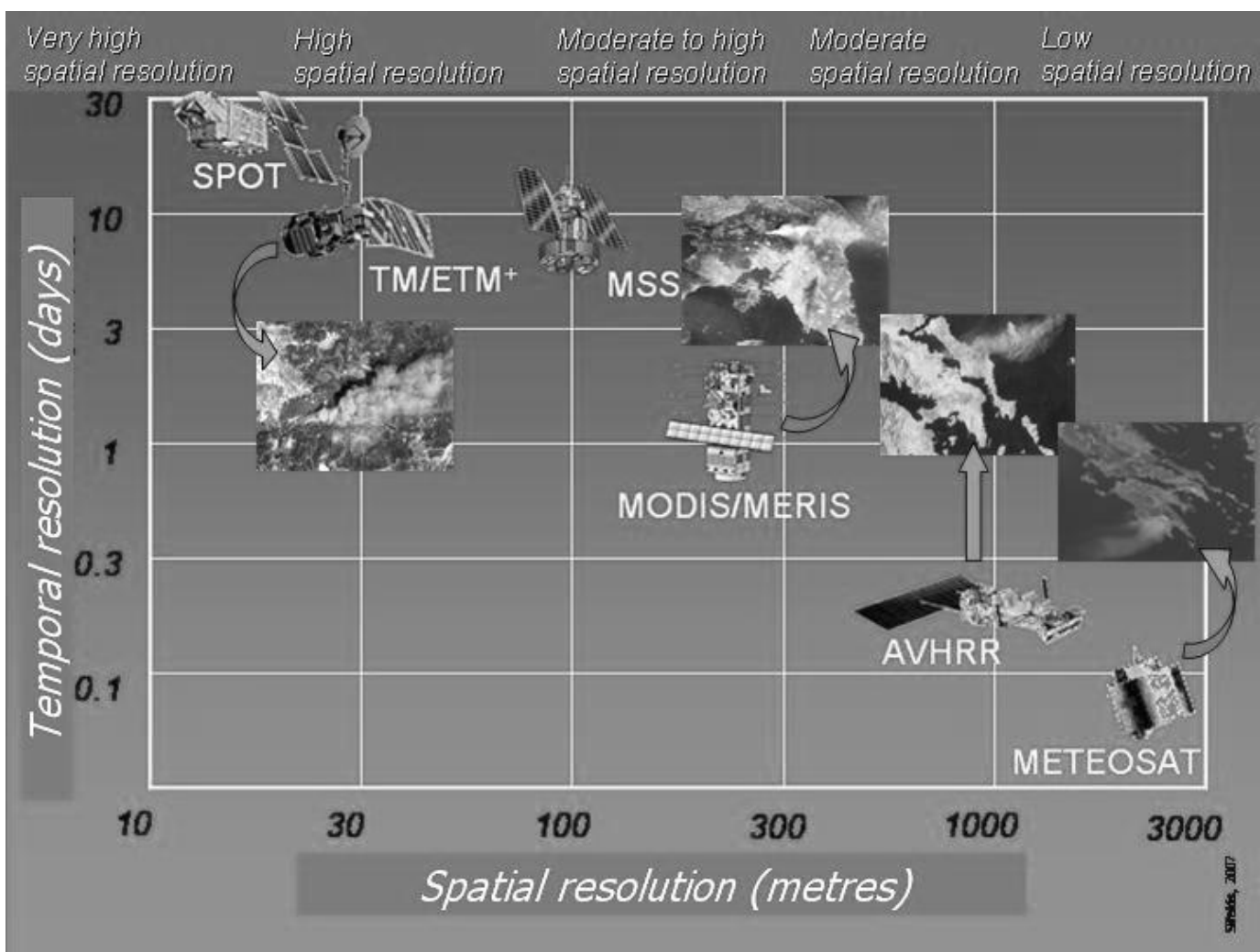

Table 1. Spectral, radiometric and spatial characteristics of the MSG-SEVIRI bands. HRV: High Resolution Visible; VIS: Visible; NIR: Near InfraRed; SWIR: Short Wave InfraRed; TIR: Thermal InfraRed; WV: Water Vapour.

\begin{tabular}{ccccc}
\hline Band & $\begin{array}{c}\text { Spectral } \\
\text { area }\end{array}$ & $\begin{array}{c}\text { Bandwidth } \\
(\boldsymbol{\mu m})\end{array}$ & Radiometric range & $\begin{array}{c}\text { Spatial resolution } \\
(\mathbf{k m}) \text { (Greece) }\end{array}$ \\
\hline HRV $(12)$ & VIS-NIR & $0.60-0.90$ & $0-459 \mathrm{w} / \mathrm{m}^{2} \mathrm{sr} \mu \mathrm{m}$ & $<2$ \\
1 & VIS & $0.56-0.71$ & $0-533 \mathrm{w} / \mathrm{m}^{2} \mathrm{sr} \mu \mathrm{m}$ & $\sim 4$ \\
2 & NIR & $0.74-0.88$ & $0-357 \mathrm{w} / \mathrm{m}^{2} \mathrm{sr} \mu \mathrm{m}$ & $\sim 4$ \\
3 & NIR & $1.50-1.78$ & $0-75 \mathrm{w} / \mathrm{m}^{2} \mathrm{sr} \mu \mathrm{m}$ & $\sim 4$ \\
4 & SWIR & $3.48-4.36$ & $0-335 \mathrm{~K}$ & $\sim 4$ \\
5 & WV & $5.35-7.15$ & $0-300 \mathrm{~K}$ & $\sim 4$ \\
6 & WV & $6.85-7.85$ & $0-300 \mathrm{~K}$ & $\sim 4$ \\
7 & TIR & $8.30-9.10$ & $0-300 \mathrm{~K}$ & $\sim 4$ \\
8 & TIR $\left(\mathrm{O}_{3}\right)$ & $9.38-9.94$ & $0-310 \mathrm{~K}$ & $\sim 4$ \\
9 & TIR & $9.80-11.80$ & $0-335 \mathrm{~K}$ & $\sim 4$ \\
10 & TIR & $11.00-13.00$ & $0-335 \mathrm{~K}$ & $\sim 4$ \\
11 & TIR $\left(\mathrm{CO}_{2}\right)$ & $12.40-14.40$ & $0-300 \mathrm{~K}$ & $\sim 4$ \\
\hline
\end{tabular}


Despite its coarse spatial resolution (of the order of $3 \mathrm{~km}$ ) recent studies demonstrate the capabilities of SEVIRI for much smaller fire detection [13]. Laneve et al. [14] suggested that SEVIRI can constitute an operational means to detect fires in the Mediterranean areas. Van den Bergh and Frost [15] have applied multi temporal approaches to detect fires based on the high update rate of SEVIRI. Umamaheshwaran et al. [16] investigated the potential of image mining methods in order to improve information extraction from SEVIRI concerning fire modeling.

SEVIRI's temporal resolution allows a quasi real time identification of new fires satisfying most users' requirements, that is, to be alerted within an average time of 10-20 minutes [17]. This is not the case with its spatial resolution and geo-location accuracy; due to its distant geostationary orbit (i.e., 36,000 km) and the renowned resolution limitations of thermal sensors SEVIRI has a ground sampling distance of the order of $4 \mathrm{~km}$ over southern Europe, which, theoretically, allows for the detection of large wildfires only. More precisely, it was estimated that the minimum detectable fire size by SEVIRI is 0.22 ha at the equator and 0.46 ha at $50^{\circ} \mathrm{N}$ [18]. Nonetheless, the elevated saturation temperature $(>335 \mathrm{~K})$ in the SWIR band of SEVIRI minimizes the saturation effect allowing for a sub-pixel fire characterization. This means that, due to the important temperature contrast between the hot spots and the background, outbursts sizing much smaller than the nominal resolution of the sensor may be detectable under certain conditions [19]. These figures may not comply with standard detection requirements of fires approximately five times smaller, namely 0.1 ha [20] but they can satisfy monitoring needs. Furthermore SEVIRI data are, for the time being, the only satellite data that can be used to improve the reliability in fire detection, and to provide synoptic and objective pictures of the situation at a country level.

With the occurrence of the disastrous wildfires of summer 2007 our objective at the Institute for Space Applications and Remote Sensing of the National Observatory of Athens (ISARS-NOA) was to investigate the potential contribution of satellite observations, particularly of those by SEVIRI, in supporting the existing services for combating wildfires. These services are currently provided by the Hellenic Fire Brigade, the General Secretariat for Civil Protection and the Forest Fire Service with little or no utilization of satellite data. During the wildfires of 2007 MSG-SEVIRI images were processed by ISARS-NOA in order to test the reliability of a real-time detection and tracking system and its complementarity to conventional means provided by the Fire Brigade.

\section{Data and Methods}

A multitude of massive wildfires broke out in many areas across Greece in the second half of August 2007. While many of these firestorms are believed to be the result of arson others were indeed the result of mere negligence or lack of timely undertaken prevention measures that would mitigate the effects of climate change in this Mediterranean region. The summer of 2007 was unprecedented in contemporary Greek history in terms of high temperatures that included three consecutive heat waves of over $40{ }^{\circ} \mathrm{C}$, and severe drought. From the end of June to early September, over 3,000 forest fires were recorded across the country. 193,656 ha of forest, olive groves and farmland were destroyed in the fires, which was the worst fire season in the past 50 years. In particular the fires in Peloponnisos accounted for approximately $70 \%$ of the total burnt land [3]. Hundreds of houses and buildings were destroyed in the blaze. 84 people lost their lives to the fires including fire fighters. The most 
destructive and lethal wildfires broke out on August 23, expanded rapidly, culminating on August 25, were not considered under control until August 30, and not extinguished until September (Figure 2).

Figure 2. Daily MODIS image acquisitions showing the evolution of fire fronts in Peloponnisos for the days of 23 (a), 24 (b), 25 (c), 26 (d), 27 (e), 28 (f), 29 (g) and 30 (h) August 2007, respectively.

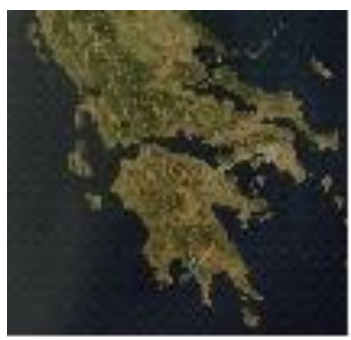

(a)

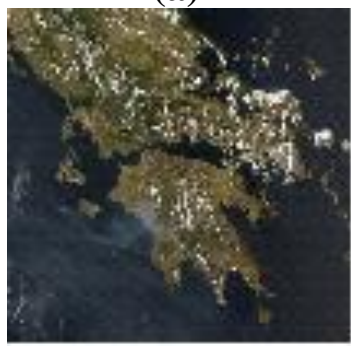

(e)

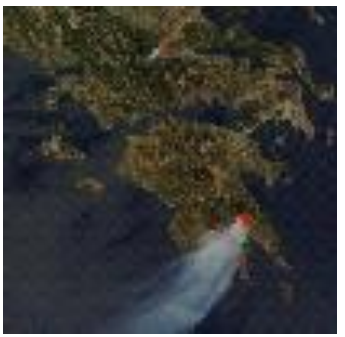

(b)

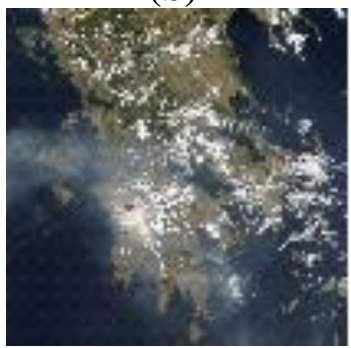

(f)

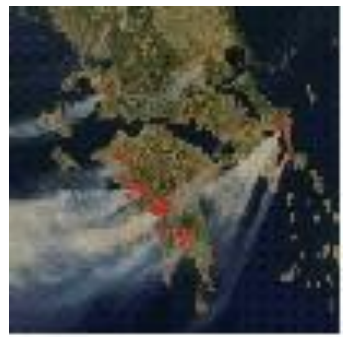

(c)

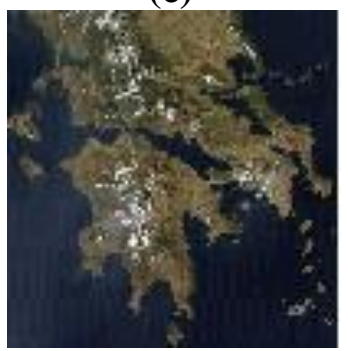

(g)

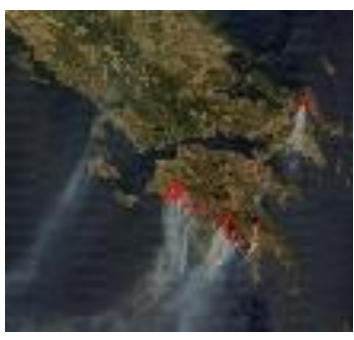

(d)

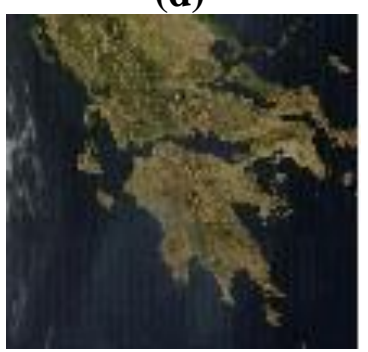

(h)

ISARS-NOA has been operating an MSG receiving station since summer 2007. During August 2007, when the extended wildfire events took place, the system's capabilities for operational detection of fire outbursts and monitoring of fronts evolution were assessed for the first time. Time series of SEVIRI data acquired during day and night were collected for the aforementioned period. All downloaded data were converted into portable gray map (pgm) image format at 16 bits. The algorithm used was the "Active Fire Monitoring Product" (FIR) for operational fire monitoring [21]. This algorithm makes use of two of the twelve MSG channels, in particular of the SWIR channel $4(3.9 \mu \mathrm{m})$ and of the TIR channel $9(10.8 \mu \mathrm{m})$. The basic principle of the algorithm is similar to that already applied for other instruments sensitive to hot spot temperature, such as GOES, AVHRR and MODIS [22-24].

In order to identify hot spot pixels (potentially active fires), the algorithm applies a combination of four threshold tests using the two aforementioned channels. The first test seeks for brightness temperatures above $290 \mathrm{~K}$ or $310 \mathrm{~K}$ (night or day respectively) in channel 4 . The second test calculates the standard deviation over 3 by 3 pixels around a central hot spot in channel 4, and this value should be greater than 2.5 in order to distinguish an actual hot spot from its natural (heated) background temperature. The third test uses the reduced sensitivity of channel 9 to hot spots; therefore brightness temperature over hot spots in this channel should be lower than brightness temperature in channel 4 during nighttime or lower by $9 \mathrm{~K}$ during daytime. The final test uses a 3 by 3 pixel standard deviation of brightness around hot spots in channel 9, which should be less than $2 \mathrm{~K}$ since fire pixels have similar brightness temperatures to the surrounding non-fire areas. 
In our case, a one-by-one examination of the above four tests showed that their consecutive application, while it favors the minimization of false alarms, has a detrimental effect on the sensitivity of the algorithm. On the other hand, using only the first and the third tests was sufficient for a reliable detection of hot spots particularly under cloud free conditions. Furthermore avoiding using the second and the fourth tests resulted in the detection of hot spots at an earlier time (i.e., 15 minutes). The following adjustments were additionally performed to the algorithm:

1. The water mask provided and used by the original algorithm [21] was not applied in our case since this would partially remove forested coastal areas of great importance for Greece. Whenever, for example, the water mask was geolocated with an accuracy of 1 pixel (i.e., approximately $4 \mathrm{~km}$ ) then many important fires by the seaside would not have been detected.

2. The application of the original algorithm finally classifies image pixels in three categories: non-fire pixels, potential fire pixels and fire pixels. While the distinction thresholds between "potential fire" and "fire" were retained, both cases were interpreted as "fire"; this choice favored the detection of more fires at the expense of false alarms.

The software code was developed in C programming language, and particular importance was given to the optimization of the execution speed. A rapid execution is required so that the detection can be achieved in real time following the data reception. The code reads and processes images in "pgm" 16bit BSQ format. The XRIT2PIC software package was used for image format transformation of the data from native format to "pgm" 16bit. The "Imagemagicka" software [25], which is suitable to create, edit and compose bitmap images, was also used for visualizing the images as "gif" movie files. The code run in bat file, and the operator could evaluate the results and warn the public authorities in less than a minute from reception of the satellite data.

\section{Results and Discussion}

The adjusted algorithm was applied to a time series of Meteosat-9 (MSG 2) SEVIRI images covering the peak period from 23 August at 15.15 until 27 August at 04.00, when the bulk of the fires occurred in Peloponnisos. The time series originally composed of 339 SEVIRI images, acquired at 15-minute intervals. 329 images were retained for the final analysis, since ten were rejected due to mediocre quality, resulting in missing $50 \%$ of strips or more covering the area of interest.

A first outburst was observed at 10.30 local time on 23 August. The processed SEVIRI image allowed locating the hot spot at the top of Mountain Parnon (Figure 3(a)). This image, although synoptic, provided important information on the fire situation in the entire Region of Peloponnisos. The Fire Brigade records confirmed that the Parnon fire was the only one burning in the entire region of Peloponnisos, consequently it was hopeful that the situation would quickly become manageable. For this reason all available fire engines, planes and helicopters, as well as firefighters and locals were sent to that area and attempted to hold back the fire. However in less than three hours a new outburst was detected in a mountainous area in central Peloponnisos. The respective SEVIRI image was acquired and processed helping to better locate the impacted site. The hot spot was situated on the top of Taygetos Mountain, a few kilometers from the previous fire (Figure 3(b)). The processed SEVIRI 
image of Figure 3(b) also revealed another strong fire signal in south Peloponnisos in the prefecture of Lakonia. At that moment there was no previous alarm or announcement concerning the latter outburst thus the SEVIRI image provided the first warning. On August 24 at 10.30 a new fire alarm occurred, and SEVIRI data located the area at the proximity of Itilon village in south Peloponnisos (Figure 3(c)). The fire spread rapidly due to strong winds. In less than two hours another fire broke out in the surroundings of Amaliada (Figure 3(d)). Two hours later a new fire occurred in the prefecture of Ilia (Zaharo) (Figure 3(d)) and one hour later a new one close to the city of Pyrgos (Figure 3(e)) threatening the archeological site of Olympia. The situation was finally out of control during the night between 24 and 25 August, as depicted in Figure 3(e), and the Ministry of Interior decreed a state of emergency. The SEVIRI data provided a synoptic yet very clear picture of this firestorm affecting not only the region of Peloponnisos, but also other places throughout Greece, including the island of Evia, and the regions of Sterea Ellas, Ipiros, and Thessalia, and even areas within the city of Athens (municipality of Papagos and cape Sounion).

Figure 4 illustrates four consecutive SEVIRI images (Figure 4(a-d)) acquired on 24 August 2007, just at the beginning of the major fire event in the village of Zaharo, indicating the velocity at which the fire spread in that area of western Peloponnisos. At 11.45 there was still no sign of fire (Figure 4(a)), however, a quarter of an hour later a large hot spot covering 8 pixels was detected (Figure 4(b)), and then, at 12.15, the number of hot pixels has tripled indicating an important increase in fire size (Figure 4(c)). Finally, at 12.30 the fire ceased spreading but seemed more intense (Figure 4(d)). It is noteworthy that in the two latter images "fire pixels" appear over the sea which, according to witnesses, is associated with pine trees burning by the coast.

The size of the minimum detectable fire depends on fire intensity, on the type of fire and on the radiative temperature of the environment. For instance, a small fire will be easier detected if it is intense or during night-time when the fire environment's temperature is lower. It is assumed that slow-burning, smoldering fires of low-intensity are, in general, more difficult to detect.

The fire event of 25 August in the residential area of Papagos (Figure 3(e)) provided us with auxiliary information relative to a qualitative estimation of the size of the minimum detectable fire during the 2007 Greek wildfires. One of the authors of this paper was able to observe in person the initial attack of the fire in the district of Papagos (at 12.30) and take ground photos. On the basis of these ground photos (Figure $5(\mathrm{a}-\mathrm{c})$ ) and of in situ observations it was possible to roughly estimate the extent and evolution of the fire in comparison to the SEVIRI imagery. This fire burnt approximately 20 ha covering, four SEVIRI pixels, which gives an average of 5 ha per pixel. The fire was brought under control in less than two hours with the help of two aerial firefighters (Figure 6). It needs to be noted that this is a rather poor detection scenario, since the event occurred during the warmest time of the day, allowing only for a rough assessment of 5 ha minimum detectable area. 
Figure 3. Major fire events as detected by SEVIRI vs. the official record (emergency call) of the Fire Brigade from 23 to 25 of August 2007.

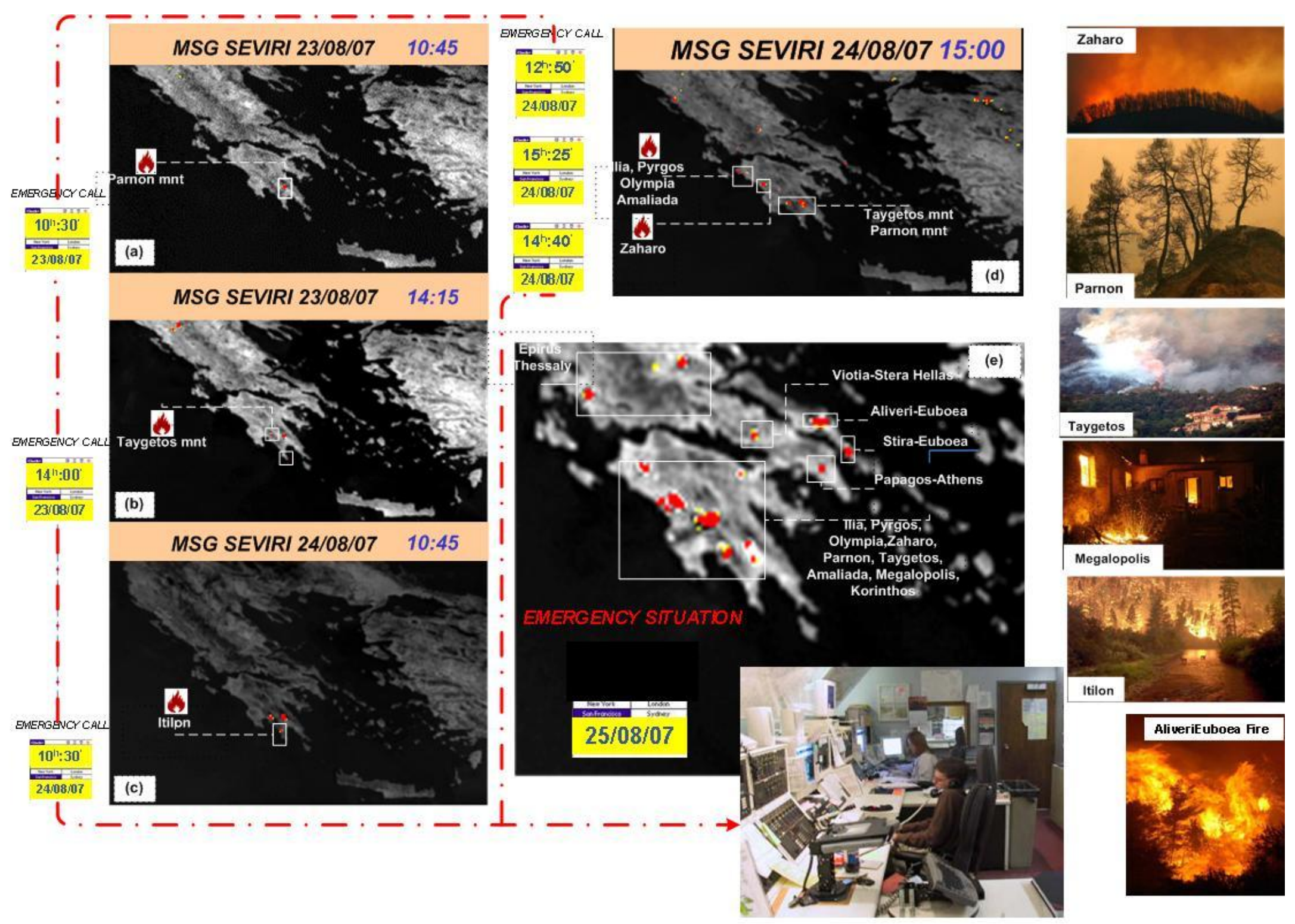


Figure 4. Four consecutive SEVIRI acquisitions on 24 August 2007 at the beginning of the event in Zaharo (centre left of the pictures); (a) at 11.45 there is no sign of fire, (b) at 12.00 a first hot spot is detected, (c) at 12.15 the fire front increases in size, (d) at 12.30 the fire increased its intensity.

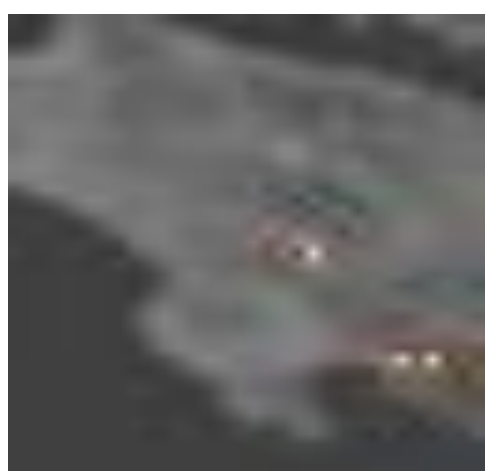

(a)

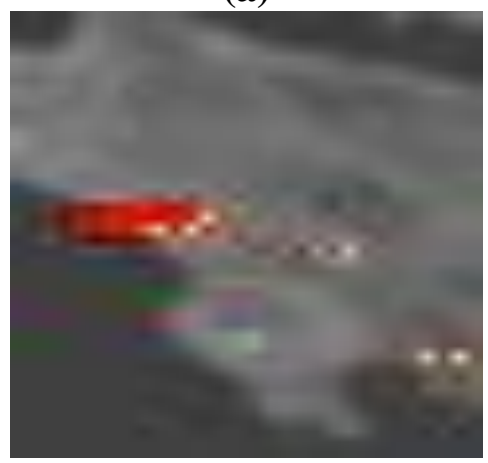

(c)

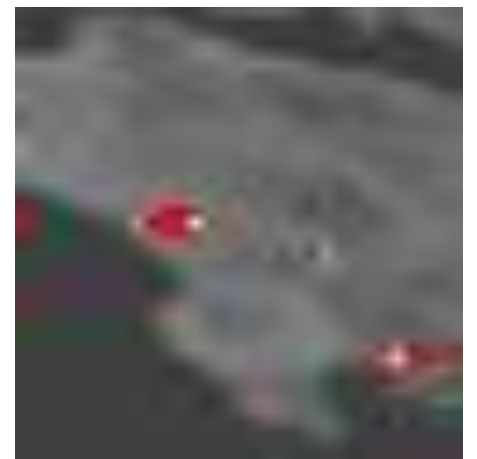

(b)

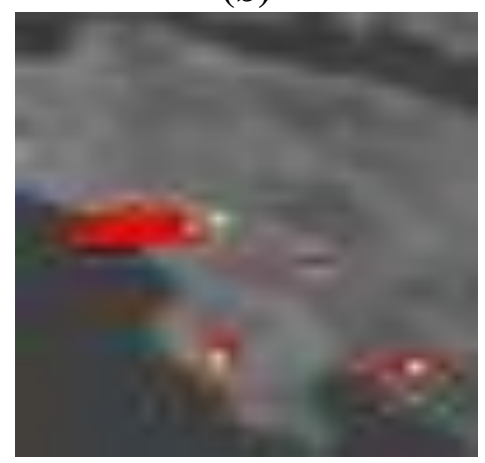

(d)

Figure 5. Sequence of photos from the Papagos fire event (residential area) on 25 August 2007: (a) shortly after the initial attack of the fire; (b) a quarter of an hour later; (c) half an hour later (photos by N. Sifakis).

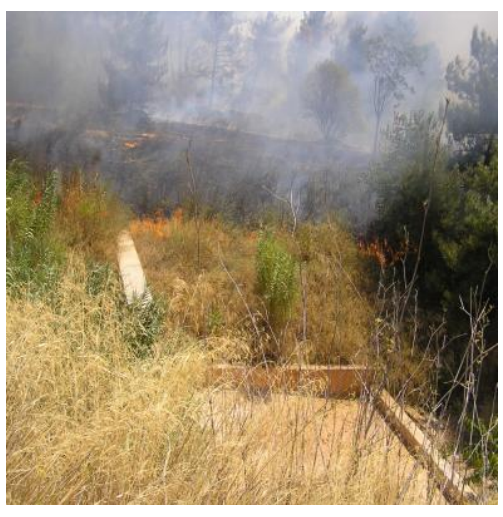

(a)

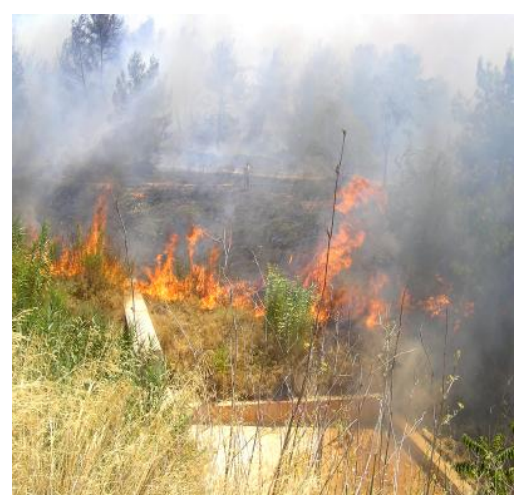

(b)

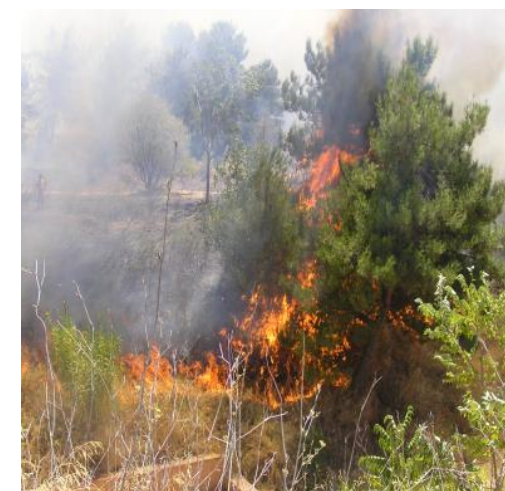

(c)

The hot spots and fire fronts were detected over Greece both during daytime and nighttime (Figure 7) while intense hot spots were detected even through thin clouds but were obscured by heavy clouds. The algorithm's sensitivity was lower during the warm hours of the day especially near and around cities, where temperature contrast was reduced due to the urban heat island. Elsewhere there was little sensitivity to the warming effect of the hot spot's environment due to the sun; this did not 
affect the detection capability of SEVIRI during daytime. Nonetheless, the detection of hot spots was more accurate during the night due to an increased thermal contrast. In some cases extended smoke plumes emitted from the wildfires were revealed by their "cooler" signature (i.e., they appeared darker) over the sea. This can be explained by the fact that part of the Earth's upwelling radiative energy was attenuated by smoke aerosols.

Figure 6. The contribution of aerial means to the rapid extinction of the fire in Papagos (25 August 2007, photo by N. Sifakis).

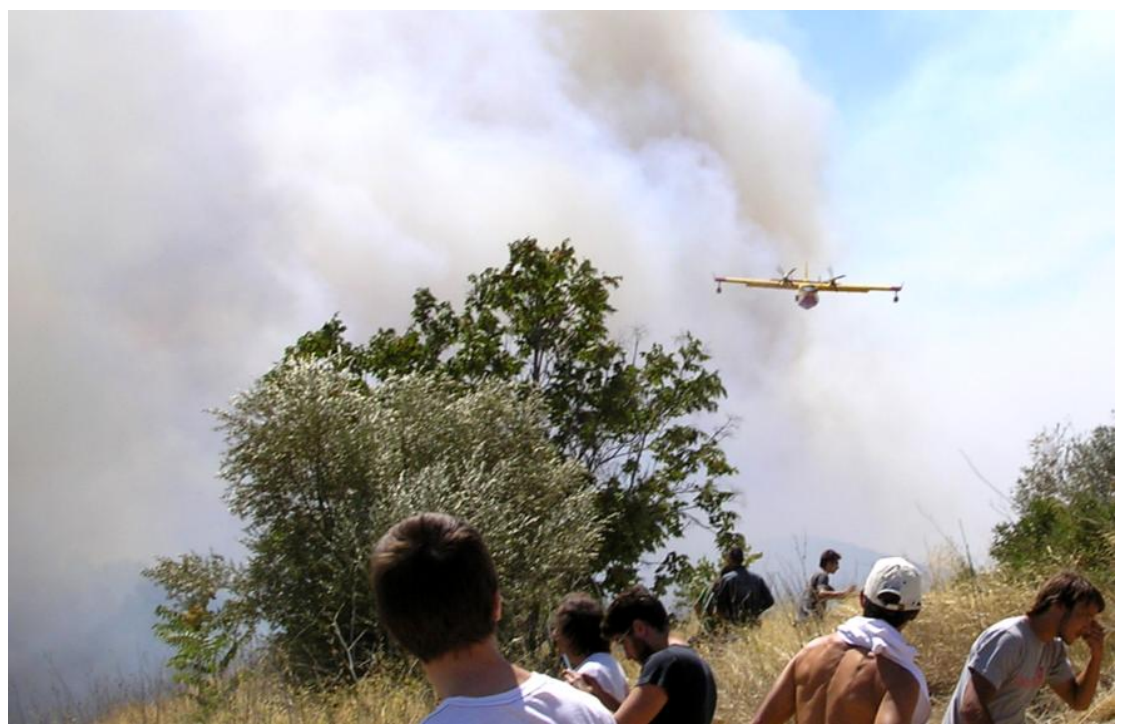

Figure 7. Two SEVIRI snap shots during the peak of fire events (August 25) in Peloponnisos; left during daytime and right during nighttime. Fire pixels appear in red while potential fire pixels appear in yellow.

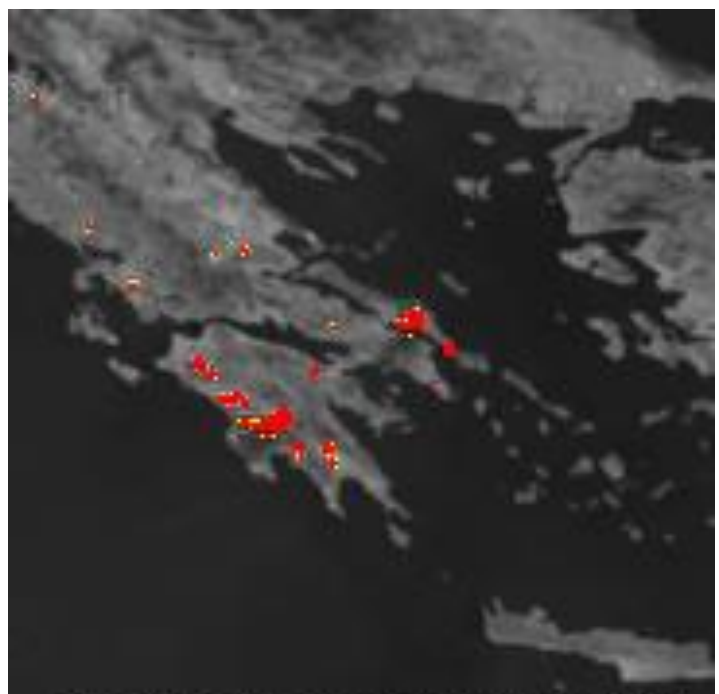

SEVIRI MIR 0708251200 UTC

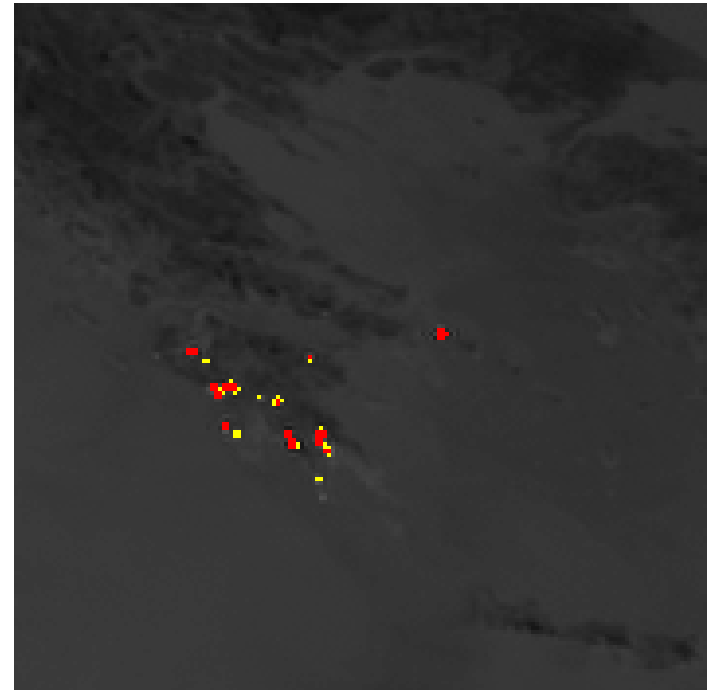

SEVIRI MIR 070825_0000 UTC

The ground truth data used for validating the results and assessing the overall accuracy of fire detection using SEVIRI data consisted of: (i) the MODIS satellite images acquired in conjunction with the SEVIRI data, (ii) the "agroforestry fire announcements" available by the Hellenic Fire Brigade. 
The MODIS data were acquired by Terra and Aqua satellites, and were downloaded from NASA's Rapid Response System. Ten MODIS images were examined in total for the hot spots associated to wildfires over Greece, and the results were compared to those obtained by MSG-SEVIRI (Table 2). The agroforestry fire announcements reference files were kindly provided by the Hellenic Fire Brigade and contained information on the following parameters: (i) number of fires, (ii) fire location (at commune level), (iii) start time (first alarm)/end time, (iv) time of intervention/time of extinction, (v) burnt area (forest, non-forest) and (vi) cause (unknown, natural, accident, deliberate).

Table 2. Comparison of hot spots observed by SEVIRI and by the respective MODIS images.

\begin{tabular}{ccccccc}
\hline Date & $\begin{array}{c}\text { SEVIRI } \\
\text { Time }\end{array}$ & $\begin{array}{c}\text { MODIS } \\
\text { Time }\end{array}$ & $\begin{array}{c}\text { Detected } \\
\text { fire events }\end{array}$ & $\begin{array}{c}\text { Omitted } \\
\text { fire events }\end{array}$ & $\begin{array}{c}\text { False } \\
\text { alarms }\end{array}$ & $\begin{array}{c}\text { Remarks on } \\
\text { satellite data }\end{array}$ \\
\hline $23 / 08 / 2007$ & $09: 00$ & $10: 30$ & 1 & 1 & 0 & Missing data \\
$23 / 08 / 2007$ & $12: 20$ & $12: 15$ & 3 & 0 & 0 & \\
$24 / 08 / 2007$ & $09: 45$ & $09: 45$ & 6 & 3 & 0 & \\
$24 / 08 / 2007$ & $11: 25$ & $11: 30$ & 8 & 5 & 0 & \\
$25 / 08 / 2007$ & $12: 05$ & $12: 00$ & 16 & 1 & 0 & \\
$26 / 08 / 2007$ & $09: 30$ & $09: 45$ & 10 & 3 & 0 & \\
$26 / 08 / 2007$ & $09: 35$ & $09: 45$ & 6 & 0 & 0 & \\
$26 / 08 / 2007$ & $11: 10$ & $11: 15$ & 16 & 1 & 0 & \\
$28 / 08 / 2007$ & $09: 20$ & $09: 15$ & 8 & 0 & Many & Clouds \\
$28 / 08 / 2007$ & $11: 00$ & $10: 00$ & 5 & 0 & Many & Clouds \\
\hline
\end{tabular}

Table 3 summarizes the comparison between the reference data as number of fire events (detected by MODIS and reported by the Hellenic Fire Brigade records) and the corresponding number of detected fires by SEVIRI throughout all of Greece for the examined period. This table gives the number of missed fires and of false alarms. In the case of the Hellenic Fire Brigade, there was only one false alarm out of 205 detected events, and the detection efficiency was as high as $82 \%$. Compared to MODIS, $15 \%$ of the fire cases were not detected by SEVIRI but there was no false alarm when the examined area was cloud-free. In all cases, the false alarm rate was less than $1 \%$, that is, well below the $5 \%$ standard requirement [26]. It should also be noted that, in quasi all cases, omitted fires appeared on the subsequent SEVIRI images received within half an hour. However an important factor that contributes to commission errors is the presence of clouds over the study area, which may introduce a significant number of false alarms particularly along their borders. These areas were excluded from the calculation of the "commission error" on Table 3.

The applied method can be considered as semi-automatic since the resulting hot spot map should be interpreted by an operator who would subsequently report to the authorities. The advantage of the adjusted algorithm is its simplicity and execution speed. After the adjustments, the algorithm missed a few fires but there were no false alarms over cloud free areas. In terms of sensitivity to radiative temperature variations, better results were obtained during nighttime when the contrast between fires 
and the environment increased. It is possible that the adjustments applied to the algorithm may also be effective for application in other geographical regions with wildfire problems that have similar climatic characteristics to Greece, such as South Africa and California.

Table 3. Omission/commission error matrix for SEVIRI vs. MODIS and $v s$. the Hellenic Fire Brigade (HFB) records.

\begin{tabular}{|c|c|c|c|c|c|}
\hline & \multicolumn{2}{|c|}{ MODIS data } & \multicolumn{2}{|c|}{ HFB records } \\
\hline & & Detected hot spots & No detection & Fire alarm & No alarm \\
\hline \multirow{3}{*}{ 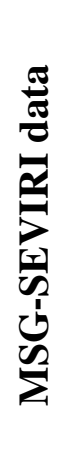 } & $\begin{array}{l}\text { Detected } \\
\text { hot spots }\end{array}$ & $\begin{array}{c}79 \\
\text { coincident } \\
(85 \%) \\
\end{array}$ & $\begin{array}{c}0 \\
\text { commission } \\
\text { (cloud-free images) }\end{array}$ & $\begin{array}{c}204 \\
\text { coincident } \\
(82 \%) \\
\end{array}$ & $\begin{array}{c}1 \\
\text { commission } \\
(<1 \%)\end{array}$ \\
\hline & No detection & $\begin{array}{c}14 \text { omissions } \\
(15 \%)\end{array}$ & & $\begin{array}{c}44 \\
\text { omissions } \\
(18 \%) \\
\end{array}$ & \\
\hline & Sum & $\begin{array}{c}93 \\
\text { events } \\
(100 \%)\end{array}$ & & $\begin{array}{c}248 \\
\text { events } \\
(100 \%)\end{array}$ & \\
\hline
\end{tabular}

\section{Conclusions}

Greece is a high risk Mediterranean country with respect to climate change effects, and the incidences of wildfires will probably increase in forthcoming years. As a part of the adaptation to climatic change policy, the authorities need to improve their current capabilities in timely and reliable detection of fire outbursts, by using tools that objectively assess fire evolution in real-time and at country level. Due to their frequent coverage, satellite geostationary systems can provide operational services for tracking wildfires.

In this work we used MSG-SEVIRI geostationary data for fire detection and tracking over Greece acquired during the disastrous wildfire period in the summer of 2007. SEVIRI data were processed using an existing image processing algorithm for fire detection [21], which was fine-tuned according to Greek conditions and priorities (i.e., increasing its sensitivity at the expense of false alarms). The obtained results were assessed against reference information on fire events provided by the Hellenic Fire Brigade. The analysis of a series of SEVIRI images acquired at a 15-minute interval showed that satellite data detected $85 \%$ of active wildfires in the Greek territory for the examined period. SEVIRI proved capable of reliably monitoring the consecutive and multiple fire events in the region of Peloponnisos. Based on these images it was possible to quickly locate all burning areas providing a synoptic picture of the disaster that may support the authorities in the engagement of the appropriate human and technical resources. In some cases, concerning mountainous and inaccessible regions, SEVIRI data provided us with the first announcement of fire occurrence in the area.

This application shows evidence that SEVIRI data can be used operationally to assist the detection of fire outbursts by improving the reliability in fire announcements and allowing real time fire front monitoring in Greece. The role of SEVIRI is more important as the fires increase in number and size. More specifically during a crisis situation SEVIRI data can provide authorities with: 
- Fire announcements (particularly in inaccessible areas and during the night) as well as validation of announcements from all other sources

- Comparative information on fire front evolution particularly useful during crisis situations and during the night

- A synoptic and objective picture of the overall fire extent and progress at country level, which are of vital importance for tactical suppression actions, including a more rational distribution of the fire brigade forces

- A rapid estimation of fronts progress in the following hours (associated to smoke plumes).

While the temporal resolution of MSG-SEVIRI data (considering also the recent possibility for 5 minutes reduced coverage) may comply with standard requirements for fire detection; its coarse spatial resolution remains the major drawback. A future thermal sensor in geostationary orbit with improved resolution is expected to locate fires accurately enough to provide safer and rapid guidance to the ground/aerial fire brigade forces. Another possible future step in this work would be to combine SEVIRI data with high spatial resolution satellite based information on land cover and fire risk in order to improve the spatial accuracy of outburst detection.

\section{Acknowledgements}

The authors would like to thank the Hellenic Fire Brigade for the valuable data provided on fire events. EUMETSAT and the Hellenic National Meteorological Service (HNMS) are acknowledged for the provision of the license under which the SEVIRI data are collected. In addition, authors are thankful to the anonymous reviewers for their useful feedback which resulted in the overall improvement of the originally submitted manuscript.

\section{References}

1. European Commission. Forest Fires in Europe; Report No. 7/2006; Institute for Environment and Sustainability, Joint Research Centre, European Commission: Ispra, Italy, 2006.

2. Running, S.W. Climate change: Is global warming causing more, larger wildfires? Science 2006, 313, 927-928.

3. Kontoes, C.C.; Sifakis, N.; Keramitsoglou, I. GMES burn scar mapping kicks into full gear after 2007 wildfires in Greece. Windows on GMES 2009, Issue 3, 58-63.

4. Psarros, C.; Theleritis, C.G.; Martinaki, S.; Bergiannaki, I.D. Traumatic reactions in firefighters after wildfires in Greece. Lancet 2008, 371, 301.

5. Justice, C.O.; Korontzi, S.A. A review of satellite fire monitoring and the requirements for global environmental change research. In Global and Regional Vegetation Fire Monitoring From Space: Planning a Coordinated International Effort; Ahem, F., Goldammer, G., Justice, C.O., Eds.; SPB Academic Publishing: The Hague, The Netherlands, 2001; pp. 1-18.

6. Lentile, L.B.; Holden, Z.; Smith, A.M.S.; Falkowski, M.J.; Hudak, A.T.; Morgan, P.; Lewis, S.A.; Gessler, P.E.; Benson, N.C. Remote sensing techniques to assess active fire and post-fire effects. Int. J. Wildland Fire 2006, 15, 319-345. 
7. Kaufman, Y.J.; Setzer, A.; Justice, C.; Ticker, C.J.; Fung, I. Remote sensing of biomass burning in the tropics. In Fires in the Tropical Biota, Ecosystem Processes and Global Challenges; Goldammer, J.G., Ed.; Springer-Verlag: Berlin, Germany; New York, NY, USA, 1990; pp. 371-399.

8. Flasse, S.P.; Ceccato, P. A contextual algorithm for AVHRR fire detection. Int. J. Remote Sens. 1996, 17, 419-424.

9. Cuomo, V.; Lasaponara, R.; Tramutoli, V. Evaluation of a new satellite-based method for forest fire detection. Int. J. Remote Sens. 2001, 22, 1799-1826.

10. Justice, C.; Giglio, L.; Korontzi, S.; Owens, J.; Morisette, J.T.; Roy, D.; Descloitres, J.; Alleaume, S.; Petitcolin, F.; Kaufman, Y. The MODIS fire products. Remote Sens. Environ. 2002, 83, 244-262.

11. Kaufman, Y.J.; Ichoku, C.; Giglio, L.; Korontzi, S.; Chu, D.A.; Hao, W.M.; Li, R.R.; Justice, C.O. Fire and smoke observed from the Earth Observing System MODIS instrument-Products, validation, and operational use. Int. J. Remote Sens. 2003, 24, 1765-1781.

12. Wooster, M.J.; Zhukov, B.; Oertel, D. Fire radiative energy for quantitative study of biomass burning: Derivation from the BIRD experimental satellite and comparison to MODIS fire products. Remote Sens. Environ. 2003, 86, 83-107.

13. Roberts, G.; Wooster, M.J. Fire detection and fire characterization over Africa using Meteosat SEVIRI. IEEE Trans. Geosci. Remote Sens. 2008, 46, 1200-1218.

14. Laneve, G.; Castronuovo, M.; Cadau, E.G. Continuous monitoring of forest fires in Mediterranean Area using MSG. IEEE Trans. Geosci. Remote Sens. 2006, 44, 2761-2768.

15. Van den Bergh, F.; Frost, P.E. A Multi Temporal Approach to Fire Detection Using MSG Data. In Proceedings of International Workshop on the Analysis of Multi-Temporal Remote Sensing Images, Biloxi, MS, USA, 16-18 May 2005; pp. 156-160.

16. Umamaheshwaran, R.; Bijker, W.; Stein, A. Image mining for modeling of forest fires from Meteosat images. IEEE Trans. Geosci. Remote Sens. 2007, 45, 246-253.

17. De Santis, A.; Bastarrika, A.; Calle, A.; Casanova, J.L.; Chuvieco, E.; Fourty, T.; Kontoes, C.; Oliva, P.; Priolo, A.; Salvador, P.; San Miguel, J.; Sifakis, N.; Tsouni, A. Thematic Services for Fire: Development, Integration and Validation Plan with Traceability of Users' Requirements; SAFER Report D3010-1; December 2009.

18. Prins, E.M.; Schmetz, J.; Flynn, L.P.; Hillger, D.W.; Feltz, J.M. An overview of diurnal active fire monitoring using a suite of international geostationary satellites. In Global and Regional Vegetation Fire Monitoring from Space: Planning a Coordinated International Effort; Ahern, F.J., Goldammer, J.G., Justice, C.O., Eds.; SPB Academic Publishing: The Hague, The Netherlands, 2001.

19. Laneve, G.; Cadau, E. SEVIRI/MSG Sensor Early Fire Detection Performances Assessment. In Proceedings of 2nd GOFC/GOLD Workshop on GEO Fire Monitoring, Darmstadt, Germany, 4-6 December 2006.

20. Rauste, Y.; Sephton, A.J.; Kelhä, V.; Vainio, T.; Heikinheimo, M.; Soini, K.; Frauenberger, O.; San Miguel-Ayanz, J. Forest Fire Operational study: Requirements and Analysis Report RAR; VERSION 2.3 (AO/1-3468/98/I-DC); Report to the European Space Agency; VTT: Espoo, The Netherlands, 1999. 
21. EUMETSAT. Active Fire Monitoring with MSG Algorithm-Theoretical Basis Document; Report \#EUM/MET/REP/07/0170; Eumetsat: Darmstadt, Germany, 2007.

22. Giglio, L.; Kendall, J.D.; Justice, C.O. Evaluation of global fire detection algorithms using simulated AVHRR infrared data. Int. J. Remote Sens. 1999, 20, 1947-1985.

23. Morisette, J.T.; Giglio, L.; Csiszar, I.; Justice, C.O. Validation of the MODIS active fire product over Southern Africa with ASTER data. Int. J. Remote Sens. 2005, 26, 4239-4264.

24. Weaver, J.F.; Purdom, J.F. Observing forest fires with the GOES-8, $3.9 \mu \mathrm{m}$ imaging channel. Weather Forecast. 1995, 10, 803-808.

25. Still, M. The Definite Guide to ImageMagick; Wade, M., Ed.; Apress, Springer: New York, NY, USA, 2006.

26. Lynham, T.J.; Dull, C.W.; Singh, A. Requirements for Space-Based Observations in Fire Management: A Report by the Wildland Fire Hazard Team, Committee on Earth Observation Satellites (CEOS) Disaster Management Support Group (DMSG). In Proceedings of 2002 IEEE International Geoscience and Remote Sensing Symposium, Toronto, ON, Canada, 24-28 June 2002; pp. 762-764.

(C) 2011 by the authors; licensee MDPI, Basel, Switzerland. This article is an open access article distributed under the terms and conditions of the Creative Commons Attribution license (http://creativecommons.org/licenses/by/3.0/). 